\title{
Closure of orocutanous fistula using a pedicled expanded deltopectoral flap
}

Chenicheri Balakrishnan MD, Kailash Narasimhan MD, Tolga Gursel MD, Ollie Jackson MD, Adam Schaffner MD

C Balakrishnan, K Narasimhan, T Gursel, O Jackson, A Schaffner. Closure of orocutanous fistula using a pedicled expanded deltopectoral flap. Can J Plast Surg 2008;16(3):178180.

Orocutaneous fistulas are associated with considerable morbidity. Closures of these fistulas are a challenge to the reconstructing surgeon. The aim of treatment is to provide healthy tissue to repair both the oral and cutaneous defects. The use of an expanded pedicled deltopectoral flap for the closure of an orocutaneous fistula in a patient who has undergone bilateral neck dissection and radiation is reported.

\section{Fermeture d'une fistule bucco-cutanée à l'aide d'un lambeau deltopectoral pédiculé élargi}

Les fistules bucco-cutanées sont associées à une morbidité considérable. La fermeture de ces fistules représente un défi en chirurgie reconstructive. Le but du traitement est de fournir des tissus sains pour réparer les anomalies buccales et cutanées. Les auteurs décrivent ici l'utilisation d'un lambeau deltopectoral pédiculé élargi pour la fermeture d'une fistule buc co-cutanée chez un patient qui a subi un traitement de résection et radiothérapie bilatérales au cou.

\section{Key Words: Expanded deltopectoral flap; Orocutaneous fistula}

A fistula is an abnormal pathway between an internal cavity or organ and the surface of the body. An orofacial or orocutaneous fistula is a pathological communication between the cutaneous surface of the face and the oral cavity. Orocutanous fistulas are not common, but intraoral sinus tracts due to dental infections are common. An oral cutaneous fistula leads to esthetic problems due to the continual leakage of saliva from the oral cavity to the face. Malignancy, inflammation and trauma are the most common causes.

Due to chronic inflammation and lack of soft tissue in the area, these fistulas are a challenge to the reconstructive surgeon. Various methods have been described to close these fistulas. Although use of free tissue provides the option of single-stage closure, this may not be possible in patients who have undergone bilateral cervical lymph node dissection followed by radiation. We report a patient who underwent closure of an orocutaneous fistula using an expanded deltopectoral flap.

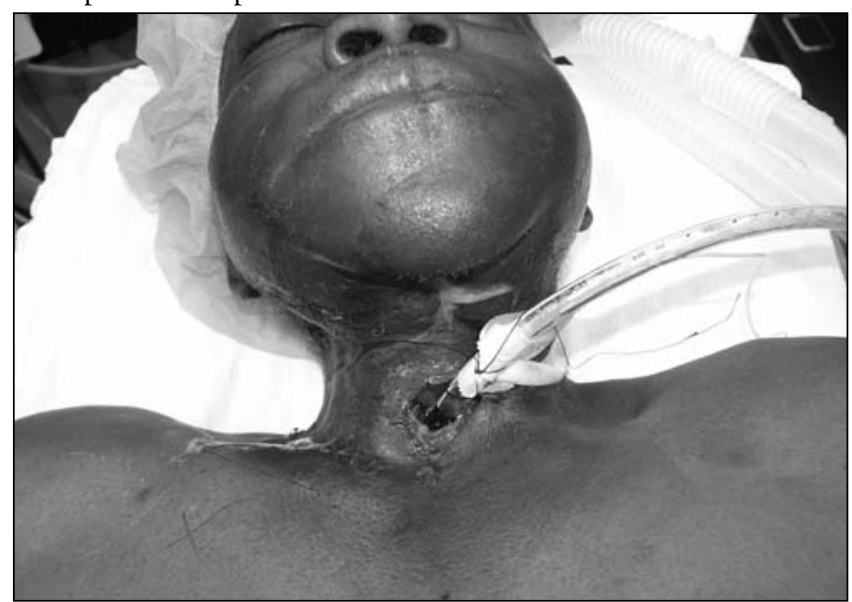

Figure 1) Orocutaneous fistula

\section{CASE PRESENTATION}

A 41-year-old man presented with a squamous cell carcinoma of the floor of the mouth with bilateral lymphadenopathy. He underwent resection of the lesion along with bilateral cervical lymph node resection. Due to the adherence of the lymph node to the internal jugular vein, both internal jugular veins had to be removed. The defect was reconstructed with a radial forearm flap for the floor of mouth and anterior tongue. He underwent a full course of postoperative radiation. During his radiation treatment, he developed an orocutaneous fistula just posterior to the mandible. Although an attempt was made to close the small fistula with local flap designed from the radial forearm flap, this was not possible due to scarring around the area (Figure 1).

A decision was made to repair the fistula using a deltopectoral flap. To obtain enough tissue and to thin the flap, a tissue expander was placed under the deltopectoral area (Figure 2). The flap was raised and tubed, with closure of the donor site

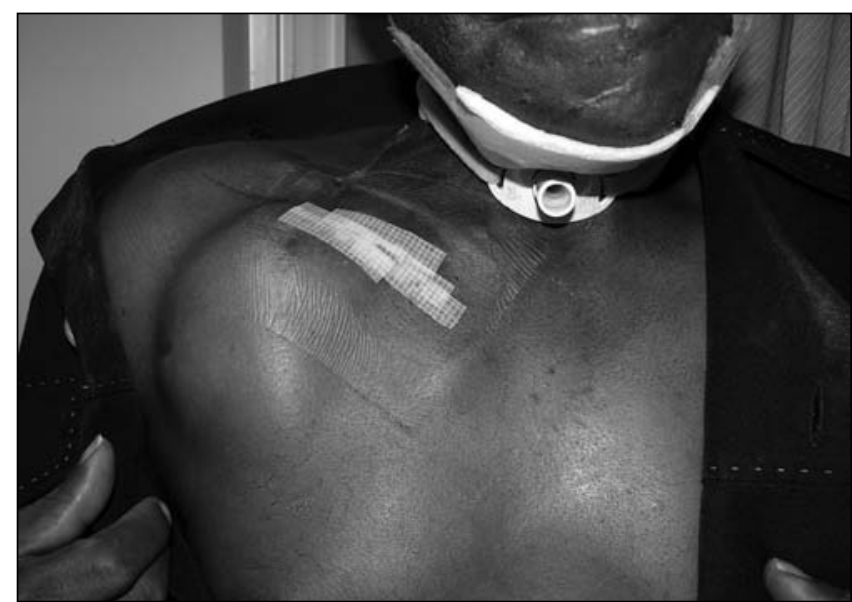

Figure 2) Expanded deltopectoral flap

Department of Plastic surgery, Wayne State School of Medicine, Detroit, Michigan, USA

Correspondence: Dr C Balakrishnan, Division of Plastic Surgery, John Dingell Veterans Administration Medical Center, 4646 John R, Detroit, Michigan 48201, USA. Telephone 313-745-3008, e-mail cbalakri@med.wayne.edu 


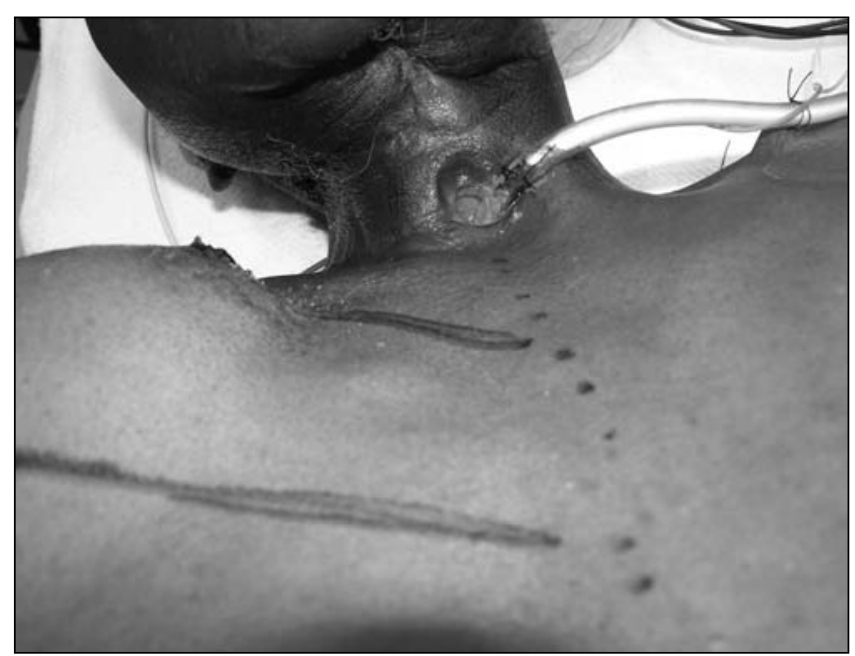

Figure 3) Flap marked out

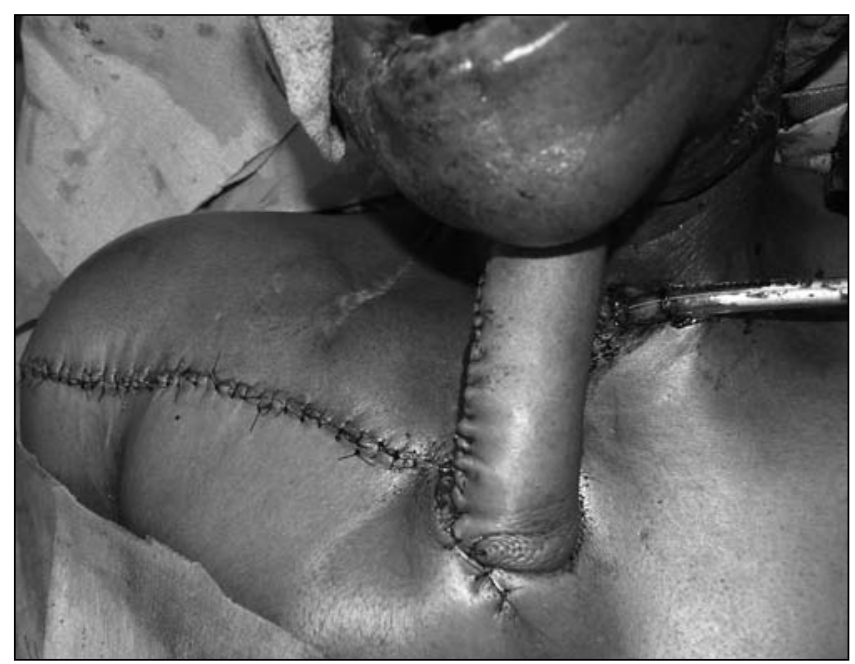

Figure 4) Flap transferred and inset with closure of donor site

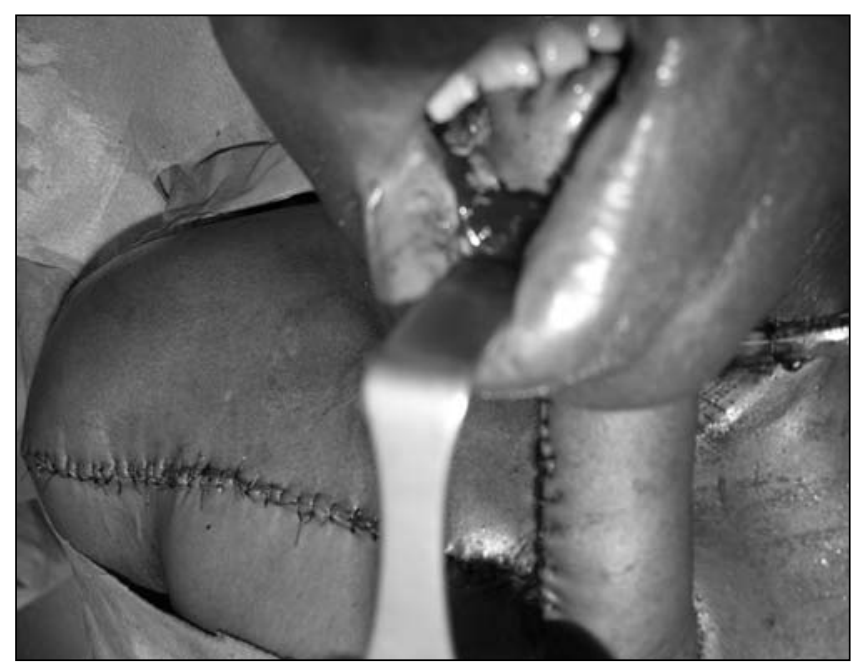

Figure 5) Intraoral part of the flap

(Figures 3 and 4). The orocutaneous fistula was repaired after excision of all scar tissue in two layers with de-epithelialization of the buried pedicle (Figure 5). The pedicle was divided at approximately three weeks (Figures 6 and 7). His tracheostomy was capped (Figure 8) and removed soon thereafter.

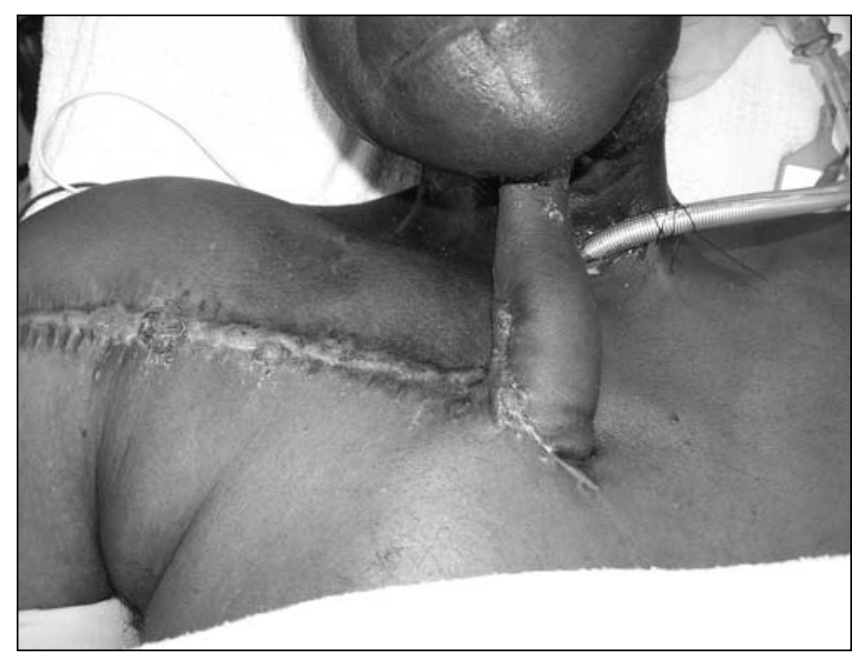

Figure 6) Flap prior to division

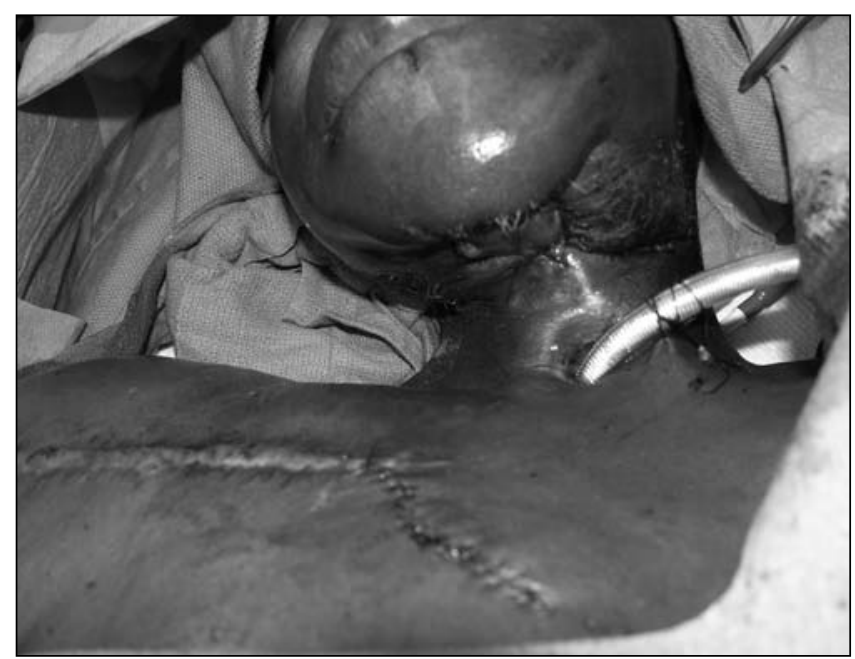

Figure 7) Pedicle divided and closed

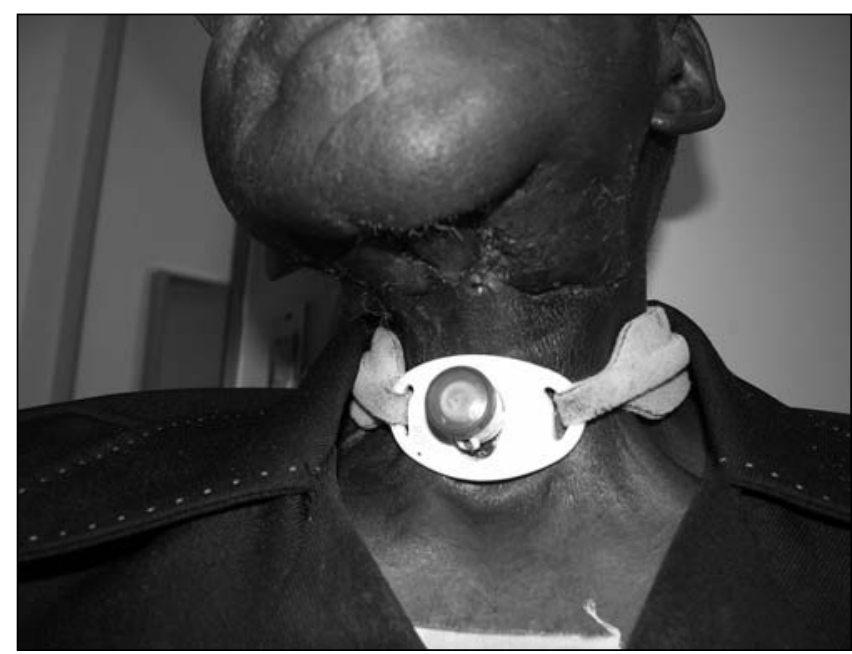

Figure 8) Three months after closure

\section{DISCUSSION}

Orocutaneous neoplastic fistulas result from the penetration of a neoplasm from the oral cavity to the outlying skin. The most common malignancy in the oral cavity is squamous cell carcinoma. Fistulas caused by squamous cell carcinoma have a poor 
prognosis because of skin lymphatic drainage into the cervical nodes. Orocutanous fistulas may occur in patients who have undergone jaw irradiation because of a previous malignancy (osteoradionecrosis).

In 1965, Bakamjian (1) described the deltopectoral flap as a two-stage reconstructive option in head and neck surgery. This is a fasciocutaneous flap based on the perforator arteries from the internal mammary artery. It served as the premier flap for reconstructing complex head and neck defects until the late 1970s (1). Due to the advancement of microsurgery, the role of the deltopectoral flap has diminished; its use is still warranted in certain selected clinical situations.

Reconstruction of pharyngostomes by using Bakamjian's deltopectoral flap modified by the use of endoscopically introduced expanders has been used for those patients in whom other techniques of choice (such as vascularized free flaps) have failed or are inapplicable either because of previous radiotherapy or because of local conditions (2). Bakamjian's deltopectoral flap, previously expanded with an expander coated with a partial-thickness skin graft and introduced endoscopically, allowed the authors to lift the flap in one operation to close the pharyngostome. This method provides reconstruction of the two walls of the pharynx, the skin graft as the inner aspect and the skin flap as the outer aspect, and the donor deltopectoral area is covered and epithelialized due to the skin graft. Thus, by means of endoscopic expansion, we used a nonaggressive technique to increase the surface area of the donor site and to increase its vascularization (delay phenomenon). Because the expander was coated with the graft, the authors were able to cover the anterior wall of the pharyngostome and the donor site in one surgical step (2).

Pre-expansion of flaps augments flap size dimensions and provides delay of tissue by opening 'choke' vessels, thus augmenting the territories of adjacent angiosomes. A secondary benefit is that the donor site, traditionally treated by skin graft, can be closed primarily (3). Expanded deltopectoral flaps have been used to cover cheek defects $(4,5)$. Due to expansion, an esthetic refinement can be achieved in the texture and colour match in comparison with the skin graft. A larger flap can be elevated to cover the acromial area by the delay effect.

The deltopectoral flap provides an excellent method of reconstruction in selected cases in which vascularized skin coverage of the neck is needed. Because an expander is used, the donor site can be closed primarily. The expanded thin skin is a better tissue match for the floor of the mouth. The deltopectoral flap also provides a valuable salvage option in situations in which other reconstructive techniques are not possible.

\section{REFERENCES}

1. Bakamjian VY. A two-stage method for pharyngoesophageal reconstruction with a primary pectoral skin flap. Plast Reconstr Surg 1965;36:174-84.

2. Serra JM, Benito JR, Monner J, Manzano M, Paloma V, Castro V. Reconstruction of pharyngostomes with a modified deltopectoral flap combining endoscopy and tissue expansion. Ann Plast Surg 1998;41:283-8.

3. Lin CH, Levin LS. Free flap expansion using balloon-assisted endoscopic technique. Microsurgery 1996;17:330-6.

4. Miyawaki T, Degner D, Jackson IT, et al. Easy tissue expansion of prelaminated mucosa-lined flaps for cheek reconstruction in a canine model. Plast Recons Surg 2002;109:1978-85.

5. Iwahira Y, Maruyam Y, Saze M, Kitayama E, Hirata A. Reconstruction of cheek defect with an expanded deltopectoral flap. Poster presented at the ASPS/PSEF/ASMS 70th Annual Scientific Meeting, Orlando, Florida, November 3-7, 2001. $<$ www.plasticsurgery.org/PSF/PSFHOME/educate/abstracts/Posters/7 77.htm> (Version current at June 6, 2008). 